\title{
The Renal Guard System for the Prevention of Contrast-Induced Acute Kidney Injury
}

\author{
Cristina Quintavalle ${ }^{1}$, Chiara Sordelli ${ }^{2}$, Giovanni Napolitano ${ }^{3}$, Gerolama Condorelli ${ }^{1}$ and Carlo Briguori ${ }^{*}$ \\ ${ }^{1}$ Department of Molecular Medicine and Medical Biotechnologies, "Federico II" University of Naples, and IEOS, CNR Naples, Italy \\ ${ }^{2}$ Interventional Cardiology and Department of Cardiology, Clinica Mediterranea, Naples, Italy \\ ${ }^{3}$ University of Cardiology, Hospital San Giuliano, Naples, Italy
}

*Corresponding author: Carlo Briguori, MD, PhD, Interventional Cardiology, Clinica Mediterranea, Via Orazio 2, Naples, I-80121, Italy, Tel: 39081/7259764; Fax: 39081/7259777; E-mail: carlobriguori@clinicamediterranea.it

Received date: May 17, 2016; Accepted date: May 26, 2016; Published date: June 2, 2016

Copyright: (C) 2016 Quintavalle C, et al. This is an open-access article distributed under the terms of the Creative Commons Attribution License, which permits unrestricted use, distribution, and reproduction in any medium, provided the original author and source are credited.

\begin{abstract}
Contrast-induced acute kidney injury (Cl-AKI) accounts for approximately $10 \%$ of all causes of hospital-acquired renal failure, causes a prolonged in-hospital stay and represents a strong predictor of poor early and late outcome. A general consensus exists on the beneficial prophylactic effect of hydration The Renal Guard system (PLC Medical System, Inc. Franklin, MA, USA) has been developed to facilitate optimal hydration therapy. This device allows to achieve high urine flow rate $(\geq 300 \mathrm{ml} / \mathrm{h}$ ) while simultaneously balancing urine output and venous fluid infusion to prevent hypovolemia. Some studies have shown that the Renal Guard system is more effective than the conventional hydration regimen in preventing $\mathrm{Cl}-\mathrm{AKI}$. A recent study suggests that the best threshold for $\mathrm{Cl}-\mathrm{AKI}$ prevention is a mean intraprocedural urine flow rate $\geq 450 \mathrm{ml} / \mathrm{h}$.
\end{abstract}

Keywords: Iodinated contrast media; Nephrotoxicity; Prevention; Antioxidant

\section{Introduction}

In the last decades percutaneous coronary, peripheral and valvular procedures have substantially increased. The administration of iodinated contrast media (CM) is essential for all these procedures. Although usually well tolerated; CM may induce acute kidney injury (AKI). CM-induced AKI (CI-AKI) has become the third cause for hospital-acquired renal failure with a prolongation of the hospital stay and consequently an increase of health costs1. Beyond that, patients developing CI-AKI are at higher risk of both a further deterioration of kidney function and an unfavorable clinical outcome [1]. The most common clinical definitions of CI-AKI are based on the increase in serum creatinine levels $\geq 25 \%$ and $\geq 0.5 \mathrm{mg} / \mathrm{dl}$ from the baseline value at 48 hours after CM administration or the need for dialysis [2]. Different strategies have been proposed to prevent this complication [3]. In this review we discuss on the potential advantages of the Renal Guard system to prevent CI-AKI.

\section{The Renal Guard System}

A general consensus exists on the beneficial effect of hydration in preventing CI-AKI [3]. Hydration induces an increase of urine flow rate (UFR), reduces the concentration of $\mathrm{CM}$ in the tubule and expedites $\mathrm{CM}$ excretion thus reducing the exposure time of tubular cells to the toxic effects of CM [4-6]. The most recommended hydration regimen is normal saline infusion at $1 \mathrm{ml} / \mathrm{kg} / \mathrm{h} 12$ hours before and 12 hours after CM exposure [3]. Limitations of this hydration regimen include 1) preclusion in urgent/emergent settings, and 2) suboptimal efficacy in high risk patients.
One approach for CI-AKI prophylaxis implies the induction and maintenance of a high UFR. The Prevention of Radiocontrast Induced Nephropathy Clinical Evaluation (PRINCE) study indicates that increasing the UFR to $\geq 150 \mathrm{ml} / \mathrm{h}$ reduces the toxic effect of CM [7]. However, this UFR was reached in $<30 \%$ of patients. In particular, in patients treated with ipotonic infusion alone UFR was $122 \pm 54 \mathrm{ml}$, whereas in those treated with ipotonic infusion plus furosemide, dopamine and mannitol UFR was $167 \pm 58 \mathrm{ml}$ [7]. The high UFR should be reached by maintaining a constant intravascular volume in order to prevent hypovolemia [7].

Theoretically, furosemide should protect the kidney by reducing the outer medullary hypoxia caused by $\mathrm{CM}$ by blocking the $\mathrm{Na}-\mathrm{K}-2 \mathrm{Cl}$ transporter in the medullary thick ascending limb [8]. However, compelling data support that neither mannitol nor furosemide offer additional protection against (but may actually exacerbate) CI-AKI as compared with saline hydration alone $[9,10]$. Significant weight loss was observed in the patients treated with furosemide, suggesting that the potentially deleterious effect of furosemide was the result of a negative fluid balance.

The Renal Guard system (PLC Medical System, Inc. Franklin, MA, USA) has been developed to facilitate optimal hydration therapy. This device allows to achieve high urine output while simultaneously balancing urine output and venous fluid infusion to prevent hypovolemia [11]. The Renal Guard system includes a) a closed loop fluid management system; b) a high volume fluid pump, c) a high accuracy dual weight measuring system; d) motion detection artifact reduction; e) a single use intravenous set and urine collection system that interfaces with a standard Foley catheter; f) real-time display of urine and replacement fluid volume; g) a timely alerts to drain the urine bag or to replace the hydration fluid bag; $f$ ) and safety features such as automatic air and occlusion detection [11] (Figure 1). 


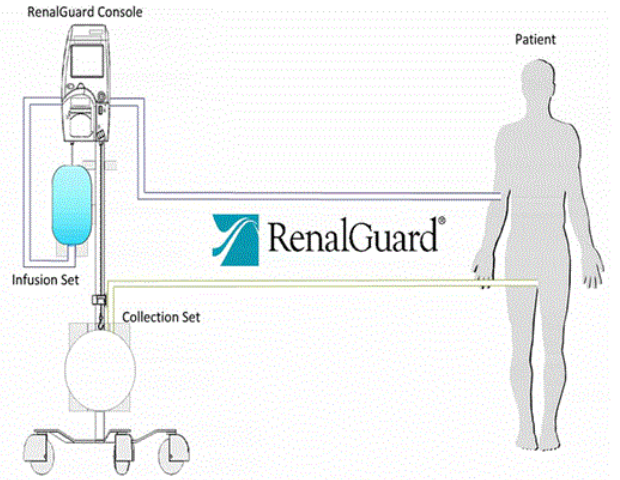

Figure 1: The Renal Guard system.

Some studies have shown that the approach of controlled, forced diuresis using the Renal Guard therapy is more effective than the conventional therapy in preventing CI-AKI in patients undergoing percutaneous coronary interventions [12-14] or transcatheter aortic valve implantation $[15,16]$. An initial bolus (priming) of $250 \mathrm{ml}$ is infused over 30 minutes.

Following the priming, furosemide $(0.25 \mathrm{mg} / \mathrm{kg})$ is administered intravenously in order to achieve high $(\geq 300 \mathrm{ml} / \mathrm{h})$ UFR. Controlled hydration by the Renal Guard system continued during the procedure and for 4 hours following the procedure. Urine flow should be monitored and maintained at the target value throughout the procedure and during the following 4 hours (Figure 2).

Additional furosemide doses are allowed in instances where there is a decrease in UFR below the target value. Briguori, et al. [12] reported a $53 \%$ relative risk reduction CI-AKI rate in patients treated by the Renal Guard system compared to the standard therapy. The beneficial effect was also documented by a lower severity of kidney damage, a lower rate of in-hospital dialysis and a smaller increase in serum cystatin $\mathrm{C}$ in the Renal Guard group than in the Control group. In the same way, Marenzi, et al. observed a $60 \%$ reduction in the incidence of CI-AKI in elective angiography patients who were treated with Renal Guard system [13].

Concerns have been raised for the high UFR obtained with the Renal Guard system due to the potential hazards of impairment in electrolyte balance and the risk of acute pulmonary edema. However, no significant changes in electrolyte balance were documented and the highly accurate, temporally matched fluid replacement observed reduced the risk of hypovolemia. Furthermore, the rate of pulmonary edema was very low [12].

In order to clarify the relationship between UFR and CI-AKI, we conducted a study assessing what should be the ideal UFR for an optimal CI-AKI prevention. We observed that the best threshold for CI-AKI prevention is a mean intraprocedural UFR $\geq 450 \mathrm{ml} / \mathrm{h}$ [17]. In high risk patients, this intraprocedural UFR target $(\geq 450 \mathrm{ml} / \mathrm{h}$ ) was reached in less than $50 \%$ of patients, and in $92 \%$ of those patients who did not developed CI-AKI, whereas an UFR $\leq 450 \mathrm{ml} / \mathrm{h}$ was observed in $68 \%$ of patients who developed CI-AKI.

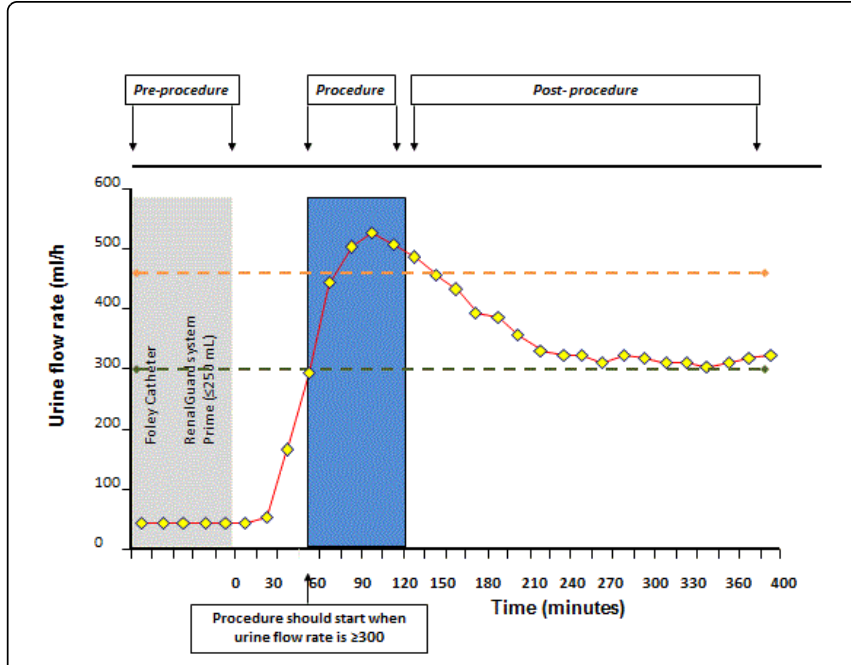

Figure 2: Diagram showing each stage of the Renal Guard therapy. The dotter-green line represents the suggested mean urine flow rate cutoff of $300 \mathrm{ml} / \mathrm{h}$. The dotter-orange line represents the suggested intraprocedural urine flow rate cutoff of $450 \mathrm{ml} / \mathrm{h}$.

On the contrary, the proposed UFR threshold $\geq 300 \mathrm{ml} / \mathrm{h}$ showed lower performance. In high risk patients, this proposed UFR target $(\geq$ $300 \mathrm{ml} / \mathrm{h}$ ) was reached in the $91.5 \%$ of patients, whereas in the remaining $8.5 \%$ patients it was constantly below the target. This cutoff has been adopted from the PRINCE study, which suggests that increasing the UFR $\geq 150 \mathrm{ml} / \mathrm{h}$ reduces the toxic effect of CM, but was never directly confirmed in the clinical practice [7]. The observed prevalent importance of the mean intraprocedural UFR emphasizes its crucial role in the CI-AKI prevention. A strong time-dependence of contrast-induced renal cell cytotoxicity has been reported [6].

Additional trials are ongoing in order to confirm these preliminary positive findings on Renal Guard system in preventing CI-AKI (Table 1). In particular, only one study compared this strategy with continuous veno-venous hemofiltration $(\mathrm{CVVH})$, which has been reported to be effective in very-high risk population [18]. Bertelli et al., indeed, compared the impact on major events of Renal Guard system $(\mathrm{n}=33)$, continuous veno-venous hemofiltration $(\mathrm{CVVH} ; \mathrm{n}=35)$ and conventional hydration (Hy; $\mathrm{n}=32$ ) in 100 patients with severe CKD scheduled for an elective percutaneous coronary and/or peripheral interventions. In-hospital dialysis occurred in none of Renal Guard patients, 7 (20\%) of CVVH patients vs $2(6.3 \%)$ of Hy group.

Futhermore, one of Renal Guard patients died at 6 month, versus 9 (25.7\%) CVVH patients and $2(6.3 \%)$ hydration protocol patients $(\mathrm{p}=0.002)$. Albeit not significant, CI-AKI occurred less frequently in the Renal Guard patients (15.2\%) than CVVH (31.4\%) and hydration protocol $(25.0 \%)(p=0.288)$ [19]. Finally, it should be clarified why UFR did not reach the proposed cutoff in approximately $9 \%$ of patients $[12,17]$. One hypothesis is that the effect of furosemide may be attenuated in the presence of renal artery stenosis. 


\begin{tabular}{|l|l|l|}
\hline Trial & Design & Registration Number \\
\hline $\begin{array}{l}\text { Evaluation of Renal Guard } \\
\text { in At-Risk Patients (CIN-RG) }\end{array}$ & $\begin{array}{l}\text { Standard therapy versus Renal Guard } \\
\text { system }\end{array}$ & NCT01456013 \\
\hline Renal Insufficiency Following Contrast Media Administration Trial III (REMEDIAL III) & $\begin{array}{l}\text { LVEDP-guided hydration versus Renal } \\
\text { Guard system }\end{array}$ & NCT02489669 \\
\hline The Use of Renal Guard System in Patients Undergoing CRT Implantation & $\begin{array}{l}\text { Standard therapy versus Renal Guard } \\
\text { system }\end{array}$ & NCT01936142 \\
\hline $\begin{array}{l}\text { The Effect of the Forced Diuresis With Matched Hydration in Reducing Acute Kidney Injury } \\
\text { During TAVI }\end{array}$ & $\begin{array}{l}\text { Standard therapy versus Renal Guard } \\
\text { system }\end{array}$ & NCT01866800 \\
\hline Renal Guard System for Prevention of Contrast Induced Nephropathy (REPRECIN) & $\begin{array}{l}\text { Standard therapy versus Renal Guard } \\
\text { system }\end{array}$ & NCT02029820 \\
\hline
\end{tabular}

Table 1: Ongoing studies on the RenalGuard system in CI-AKI prevention. LVEDP: Left Ventricular End Diastolic Pressure; CRT: Cardiac Resynchronization Therapy.

Contrast-enhanced ultrasound, based on the injection of an intravascular biocompatible tracer (that is, galactose microparticle suspension containing microbubbles [Levovist]), allows the quantification of renal tissue perfusion [20]. This promising noninvasive method seems to be ideal for screening patients with suspected renal artery stenosis. Future studies using contrast-enhanced ultrasound should clarify the role of renal artery stenosis on the efficacy of the Renal Guard therapy.

\section{Conclusion}

AKI may complicate CM exposure. The Renal Guard system seems to be helpful in preventing CIAKI by allowing a high UFR and maintaining an optimal fluid balance.

\section{References}

1. Chertow GM, Burdick E, Honour M, Bonventre JV, Bates DW (2005) Acute kidney injury, mortality, length of stay, and costs in hospitalized patients. J Am Soc Nephrol 16: 3365-3370.

2. Bellomo R, Kellum JA, Ronco C (2004) Defining acute renal failure: physiological principles. Intensive Care Med 30: 33-37.

3. Stacul F, van der Molen AJ, Reimer P, Webb JA, Thomsen HS, et al. (2011) Contrast induced nephropathy: updated ESUR Contrast Media Safety Committee guidelines. Eur Radiol 21: 2527-2541.

4. Trivedi HS, Moore H, Nasr S, Aggarwal K, Agrawal A, et al. (2003) A randomized prospective trial to assess the role of saline hydration on the development of contrast nephrotoxicity. Nephron Clin Pract 93: C29-34.

5. Bader BD, Berger ED, Heede MB, Silberbaur I, Duda S, et al. (2004) What is the best hydration regimen to prevent contrast media-induced nephrotoxicity? Clin Nephrol 62: 1-7.

6. Romano G, Briguori C, Quintavalle C, Zanca C, Rivera NV, et al. (2008) Contrast agents and renal cell apoptosis. Eur Heart J 29: 2569-2576.

7. Stevens MA, McCullough PA, Tobin KJ, Speck JP, Westveer DC, et al. (1999) A prospective randomized trial of prevention measures in patients at high risk for contrast nephropathy: results of the P.R.I.N.C.E. Study. Prevention of Radiocontrast Induced Nephropathy Clinical Evaluation. J Am Coll Cardiol 33: 403-411.

8. Liss P, Nygren A, Ulfendahl HR, Erikson U (1999) Effect of furosemide or mannitol before injection of a non-ionic contrast medium on intrarenal oxygen tension. Adv Exp Med Biol 471: 353-359.
9. Solomon R, Werner C, Mann D, D'Elia J, Silva P (1994) Effects of saline, mannitol, and furosemide to prevent acute decreases in renal function induced by radiocontrast agents. $\mathrm{N}$ Engl J Med 331: 1416-1420.

10. Weinstein JM, Heyman S, Brezis M (1992) Potential deleterious effect of furosemide in radiocontrast nephropathy. Nephron 62: 413-415.

11. Dorval JF, Dixon SR, Zelman RB, Davidson CJ, Rudko R, et al. (2012) Feasibility study of the Renal Guard balanced hydration system: a novel strategy for the prevention of contrast-induced nephropathy in high risk patients. International journal of cardiology 166: 482-486.

12. Briguori C, Visconti G, Focaccio A, Airoldi F, Valgimigli M, et al. (2011) Renal Insufficiency After Contrast Media Administration Trial II (REMEDIAL II): Renal Guard System in high-risk patients for contrastinduced acute kidney injury. Circulation 124: 1260-1269.

13. Marenzi G, Ferrari C, Marana I, Assanelli E, De Metrio M, et al. (2012) Prevention of contrast nephropathy by furosemide with matched hydration: the MYTHOS (Induced Diuresis With Matched Hydration Compared to Standard Hydration for Contrast Induced Nephropathy Prevention) trial. JACC Cardiovasc Interv 5: 90-97.

14. Usmiani T1, Andreis A, Budano C, Sbarra P, Andriani M, et al. (2016) AKIGUARD (Acute Kidney Injury GUARding Device) trial: in-hospital and one-year outcomes. J Cardiovasc Med (Hagerstown) 17: 530-537.

15. Visconti G, Focaccio A, Donahue M, Golia B, Marzano A, et al. (2016) Renal Guard System for the prevention of acute kidney injury in patients undergoing transcatheter aortic valve implantation. EuroIntervention 11: e1658-e1661.

16. Barbanti M, Gulino S, Capranzano P, Imme S, Sgroi C, et al. (2015) Acute Kidney Injury With the Renal Guard System in Patients Undergoing Transcatheter Aortic Valve Replacement: The PROTECT-TAVI Trial (PROphylactic effecT of furosEmide-induCed diuresis with matched isotonic intravenous hydraTion in Transcatheter Aortic Valve Implantation). JACC Cardiovasc Interv 8: 1595-1604.

17. Briguori C, Visconti G, Donahue M, De Micco F, Focaccio A, et al. (2016) RenalGuard system in high-risk patients for contrast-induced acute kidney injury. Am Heart J 173: 67-76.

18. Marenzi G, Marana I, Lauri G, Assanelli E, Grazi M, et al. (2003) The prevention of radiocontrast-agent-induced nephropathy by hemofiltration. N Engl J Med 349: 1333-1340.

19. Bertelli L, Politi L, Roversi S, Bartolacelli Y, Perrone S, et al. (2012) Comparison Of Renal Guard System, Continuous Venovenous Hemofiltration And Hydration In High-Risk Patients For ContrastInduced Nephropathy. J Am Coll Cardiol 59: E96-E96.

20. Ciccone MM, Cortese F, Fiorella A, Scicchitano P, Cito F, et al. (2011) The clinical role of contrast-enhanced ultrasound in the evaluation of renal artery stenosis and diagnostic superiority as compared to traditional echo-color-Doppler flow imaging. Int Angiol 30: 135-139. 